\title{
Closed incision management with negative pressure wound therapy after forelimb amputation in a dog
}

\section{Incisionele negatieve-druktherapie na voorpootamputatie bij een hond}

\author{
${ }^{1}$ M.L. Go, ${ }^{1}$ N. Vallarino, ${ }^{1}$ N. Devriendt, ${ }^{1}$ B. Van Goethem, ${ }^{1}$ I. Polis, ${ }^{2}$ E. Stock, ${ }^{1}$ H. de Rooster \\ ${ }^{1}$ Small Animal Department \\ ${ }^{2}$ Department of Medical Imaging of Domestic Animals and Orthopedics of Small Animals \\ Faculty of Veterinary Medicine, Ghent University \\ Salisburylaan 133, B-9820 Merelbeke, Belgium
}

hilde.derooster@ugent.be

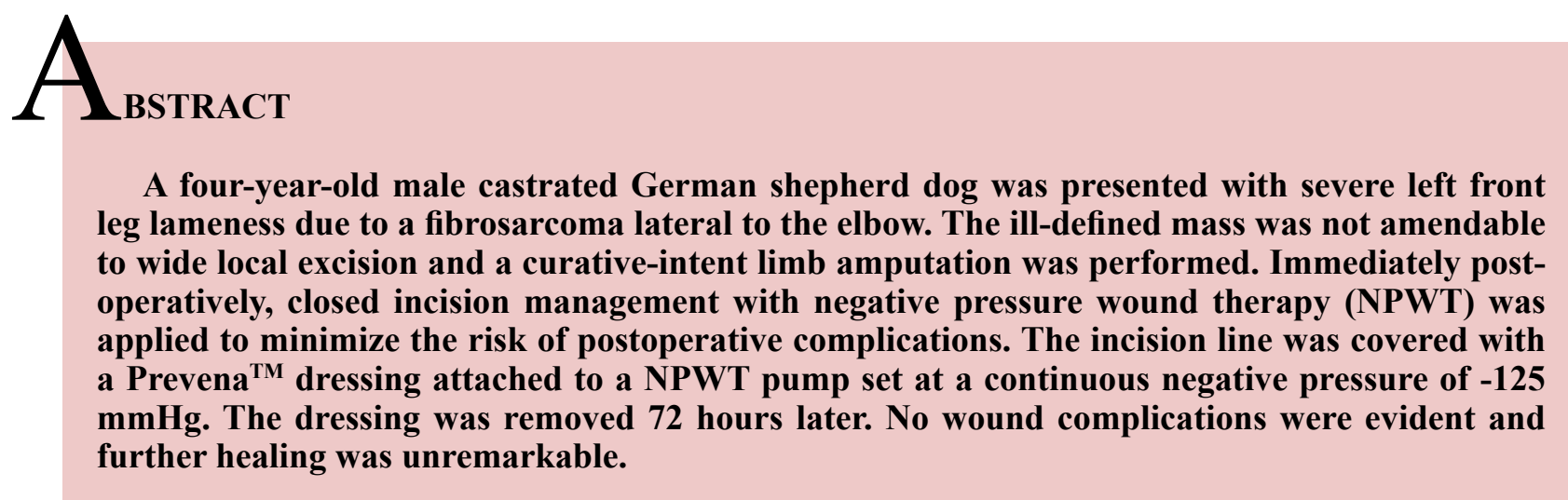

\section{SAMENVATTING}

Een vier jaar oude, mannelijke, gecastreerde Duitse herder werd aangeboden met erg manken op de linkervoorpoot ten gevolge van een fibrosarcoma lateraal van de elleboog. Omdat een wijde excisie van de slecht omschreven tumor onmogelijk was, werd er besloten om een pootamputatie uit te voeren.

Onmiddellijk postoperatief werd incisionele negatieve-druktherapie toegepast om het risico op postoperatieve complicaties te minimaliseren. Over de incisielijn werd een Prevena ${ }^{\mathrm{TM}}$ wondverband aangebracht, verbonden met een negatieve-drukpomp ingesteld op een continue druk van $-125 \mathrm{mmHg}$. Het verband werd 72 uur later verwijderd. Er traden geen complicaties op en de verdere heling verliep probleemloos.

\section{INTRODUCTION}

Negative pressure wound therapy (NPWT) involves placing a dressing onto the wound bed, creating an adhesive, airtight seal and extracting fluids from the wound through a vacuum pump (Howe, 2015; Perry et al., 2015). This way, a closed environment is created, in which wound healing is promoted (Howe, 2015). The main beneficial effects of NPWT involve the removal of exudates, the reduction of tissue edema, the increase of perfusion, the mechanical stimulation and the enhanced formation of granulation tissue (Howe, 2015; Nolff et al., 2015b). The pump can be programmed in a continuous or intermittent way, and the standard pressure is $-125 \mathrm{mmHg}$ (Birke-Sorensen et al., 2011). Of the various types of pumps, the portable V.A.C. Freedom (KCI, Texas, USA) device is very convenient in dogs as it can be incorporated into a patient's harness (Pitt and Stanley, 2014).

The initial indication of NPWT in human patients was the treatment of open wounds but currently, many new indications have emerged (Ingargiola et al., 2013). Despite its popularity in human medicine, the use of specialized NPWT systems in veterinary medicine remains limited (Nolff and Meyer-Lindenberg, 2016). Indications in veterinary medicine include various wounds, such as acute, subacute, chronic, traumatic and dehisced wounds, skin grafts, skin flaps, partial-thickness burns and closed incisions (Howe, 2015). Several veterinary case reports and case series have been published involving open wound treatment (Ben-Amotz et al., 2007; Guille et al., 2007; Mullally et al., 2010) and skin grafts (Stanley et al., 2013; Or et al., 2017). Regarding closed incision NPWT, only one 
case report (Nolff et al., 2015a) and one retrospective controlled clinical study (Perry et al., 2015) have been reported in the veterinary literature so far.

The Prevena Incision Management System (Prevena Therapy, KCI USA, Inc, Texas, USA) is designed for closed incision management (CIM) and is used immediately after primary skin closure on sutured or stapled wounds (KCI Licensing Inc., 2016a) (Figure 1).

In the current case report, the application of the CIM device Prevena in a large breed dog after amputation of the left forelimb and the resulting wound healing are described.

\section{CASE REPORT}

A four-year-old, male, castrated German shepherd dog was presented to the Small Animal Department, Faculty of Veterinary Medicine, Ghent University with severe lameness on the left front leg. Six months before presentation, the dog had gradually become lame on the left front leg. The local veterinarian administered an intra-articular injection with corticosteroids in the left elbow and instituted a systemic anti-inflammatory drug treatment. Initially, the dog responded well and the lameness improved, but gradually, it became worse again.

On physical examination, the dog appeared alert. Orthopedic inspection revealed a non-weight-bearing lameness of the left front leg. Severe swelling of the soft tissues at the lateral aspect of the left elbow was noticed, and the range of motion of the left elbow joint was severely compromised. A distinct pain reaction could be evoked upon manipulation of the elbow joint.

Medio-lateral and cranio-caudal radiographic projections of the left elbow joint confirmed the presence of a large, focal soft tissue swelling centred on the lateral epicondyle and distal metaphysis of the humerus. An amorphous periosteal reaction was present at the lateral aspect of the distal humeral metaphysis, associated with severe thinning and loss of delineation of the bone cortex at this level (Figure 2A). A Codman's triangle was visible at the caudal aspect of the distal humeral diaphysis. (Figures $2 \mathrm{~B}$ and 2C). The medullary cavity at the level of the distal humeral dia-physis and metaphysis had a heterogeneous appearance with the presence of permeative osteolysis and ill-defined small sclerotic areas with an ill-defined transition zone towards normal bone. An ill-defined sclerotic lesion was present in the proximal radial diaphysis, without other abnormalities being present at this bone. The radiographic diagnosis of an aggressive bone lesion, most likely a primary bone tumor or an invasive soft tissue tumor, centred on the distal humeral metaphysis, was made. The focal medullary opacity in the radius was interpreted as a bone infarct, which may be associated with a primary bone tumor.

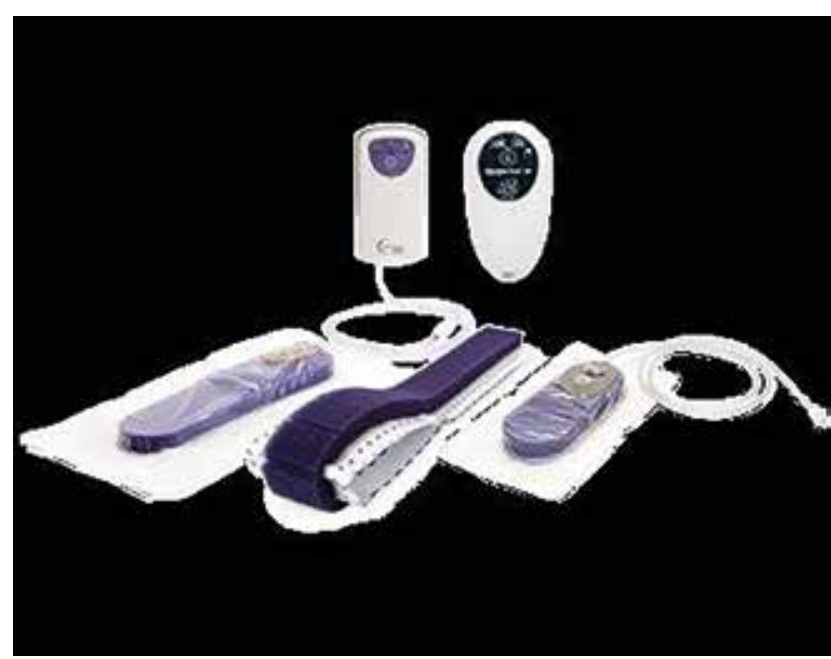

Figure 1. Prevena Incision Management System for closed incision management (KCI Licensing, 2016a).

Thoracic radiographs were taken, on which no metastases could be detected.

The dog was anesthetized to take a biopsy. Intravenous premedication consisted of a combination of 5 $\mu \mathrm{g} / \mathrm{kg}$ dexmedetomidine (Dexdomitor, Orion Corporation, Espoo, Finland), $0.2 \mathrm{mg} / \mathrm{kg}$ midazolam (Midazolam B.Braun, B.Braun Melsungen AG, Melsungen, Germany) and $0.3 \mathrm{mg} / \mathrm{kg}$ methadone (Comfortan, Eurovet Animal Health B.V., Bladel, the Netherlands). Anesthesia was induced and maintained with $2.5 \mathrm{mg} /$ $\mathrm{kg}$ propofol IV (Propovet Multidose, Abbott Laboratories, Berkshire, United Kingdom) given to effect. Two 8-mm punch biopsies were taken at the punctum maximum of the soft tissue swelling. After recovery, the dog was discharged on $2 \mathrm{mg} / \mathrm{kg}$ tramadol (Tramadol EG, Eurogenerics S.A., Brussels, Belgium) 3x/ day and $2 \mathrm{mg} / \mathrm{kg}$ cimicoxib (Cimalgex, Vétoquinol S.A., Lure, France) 1x/day while awaiting the biopsy results. The histopathological diagnosis was a soft tissue tumor, more specific a fibrosarcoma with intermediate grade.

Since the tumor was not amendable to local excision due to its location, amputation of the left front leg was advised as a potentially curative-intent surgery. The owners were informed about an ongoing clinical trial on CIM for seroma prevention after limb amputation. In consultation with the surgeon, they agreed to participate in the study and signed an informed owner consent.

On the day of surgery, the dog received IV premedication with $5 \mu \mathrm{g} / \mathrm{kg}$ dexmedetomidine and $0.3 \mathrm{mg} /$ $\mathrm{kg}$ methadone. Prophylactic antibiotic therapy consisted of $20 \mathrm{mg} / \mathrm{kg}$ cefazoline IV (Cefazoline Sandoz, Sandoz S.A., Vilvoorde, Belgium) given prior to surgery. Anesthesia was induced with $2.5 \mathrm{mg} / \mathrm{kg}$ propofol IV and maintained with isoflurane (Isoflo, Zoetis Belgium S.A., Louvain-La-Neuve, Belgium) vaporized in oxygen using a rebreathing system. Intraoperative analgesia was provided with a constant rate infusion (CRI) of $5 \mu \mathrm{g} / \mathrm{kg} / \mathrm{h}$ fentanyl (Fentadon, Eurovet 


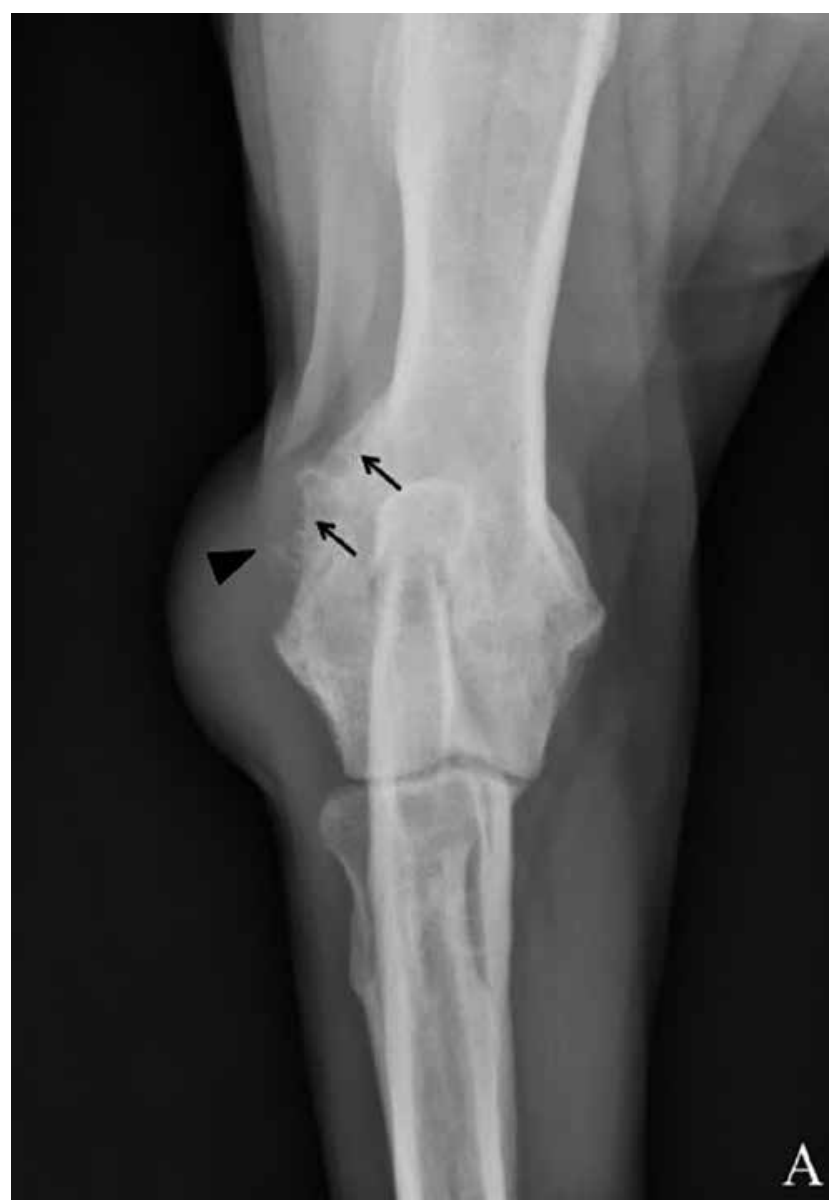

Figure 2A. Craniocaudal projection of the left elbow revealing a focal soft tissue swelling associated with an amorphous periosteal reaction (large arrow head) at the level of the lateral aspect of the distal humeral metaphysis, and severe thinning of the bone cortex at this level (thin arrows). B. and C. Mediolateral extended (B) and flexed (C) projections of the left elbow with a Codman's triangle (arrow) at the level of the caudodistal humeral diaphysis and heterogeneous aspect of the bone at the distal diaphysis and metaphysis (small arrow heads); also note the ill-defined sclerotic lesion in the proximal radius (asterisk).

Animal Health B.V., Bladel, the Netherlands). A left forelimb amputation was performed (Fossum et al., 2013). The skin incision ran from dorsal to the scapula to the shoulder, where it continued circularly to the triceps region on the lateral side as well as the medial side. Hemostasis was achieved by bipolar electrocoagulation. Muscles attached to the scapula were carefully dissected. The scapula was flipped cranially to identify the axillary artery and vein, and these vessels were ligated with 3/0 polyglecaprone 25 (Monocryl, Johnson \& Johnson Medical N.V./S.A., Diegem, Belgium) and transected. The brachial nerve plexus was infiltrated with $0.5 \mathrm{mg} / \mathrm{kg}$ bupivacaine (Marcaine $0.5 \%$, AstraZeneca, Brussels, Belgium) and sharply transected, upon which the leg was removed severing the remaining muscle bellies. Closure was performed routinely. The deeper muscle layers were closed with
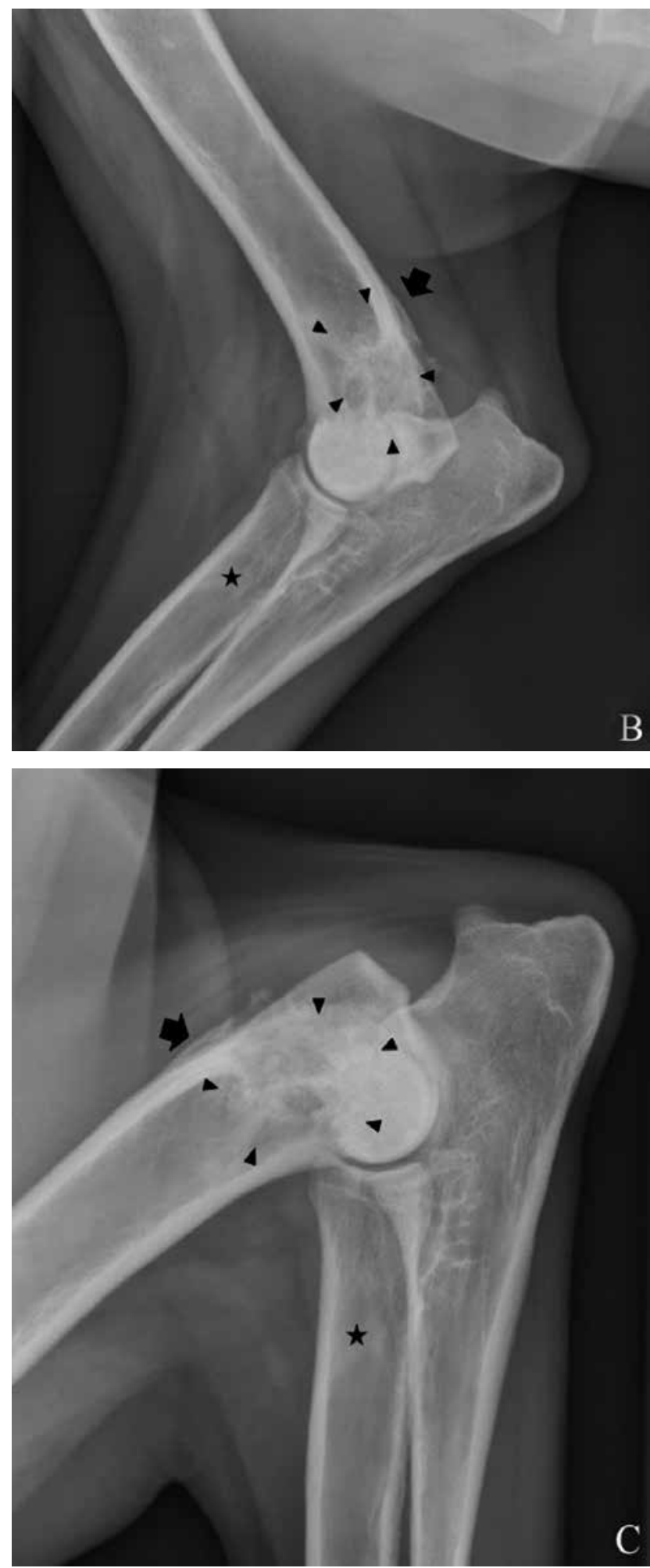

cruciate sutures in 0 polydioxanone (PDSII, Johnson \& Johnson Medical N.V./S.A., Diegem, Belgium), and the superficial muscle layers were apposed with a continuous suture pattern in $2 / 0$ polydioxanone. The deep subcutaneous layer was apposed continuously and anchored to the underlying muscle fascia with $3 / 0$ polyglecaprone 25 . The superficial subcutaneous layer was closed with a continuous pattern $3 / 0$ polyglecaprone 25 and the skin was closed intradermally with $3 / 0$ polyglecaprone. 


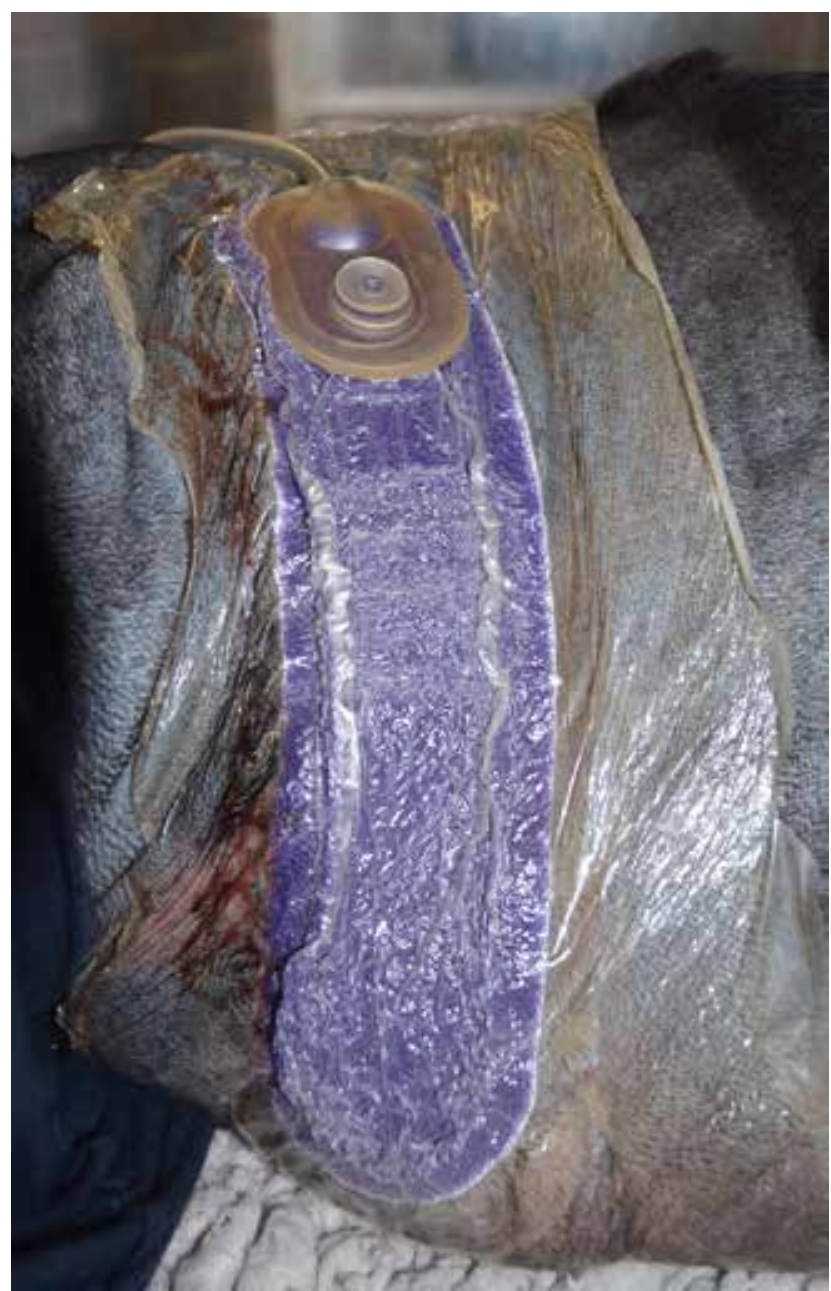

Figure 3. Image of a Prevena with a Peel \& Place dressing applied on a closed surgical incision after front limb amputation in a dog. The crumpled aspect indicates proper negative pressure. The connection towards the NPWT pump is seen dorsally (the dogs head is to the left).

Immediately after the surgery, while still in the operating room, a Prevena dressing was placed (Figure 3). The skin surrounding the suture line was first cleansed with sterile saline (Ecotainer, Braun, Melssungen, Germany), the skin was dried and then defatted with ether (Sasol, Hamburg, Germany). The dressing gauze was placed onto the closed incision in such a way that the adhesive drape surrounding it did not come in contact with the incision line. Subsequently, the dressing was connected to a V.A.C. Freedom pump device and programmed for a continuous negative pressure of $-125 \mathrm{mmHg}$.

Postoperatively, the dog was hospitalized and analgesia consisted of $0.2 \mathrm{mg} / \mathrm{kg}$ methadone every fours hours, combined with daily $2 \mathrm{mg} / \mathrm{kg}$ cimicoxib. Three hours after the surgery, the patient seemed alert but nervous. The Prevena ${ }^{\mathrm{TM}}$ dressing was still present but the negative pressure was not retained, so the dressing needed to be changed and the NPWT was reapplied. The Glasgow pain score was used to assess pain during hospitalization, and a decrease in pain level was observed over time. The bandage was removed after 72 hours; at that time, the incision line was dry and

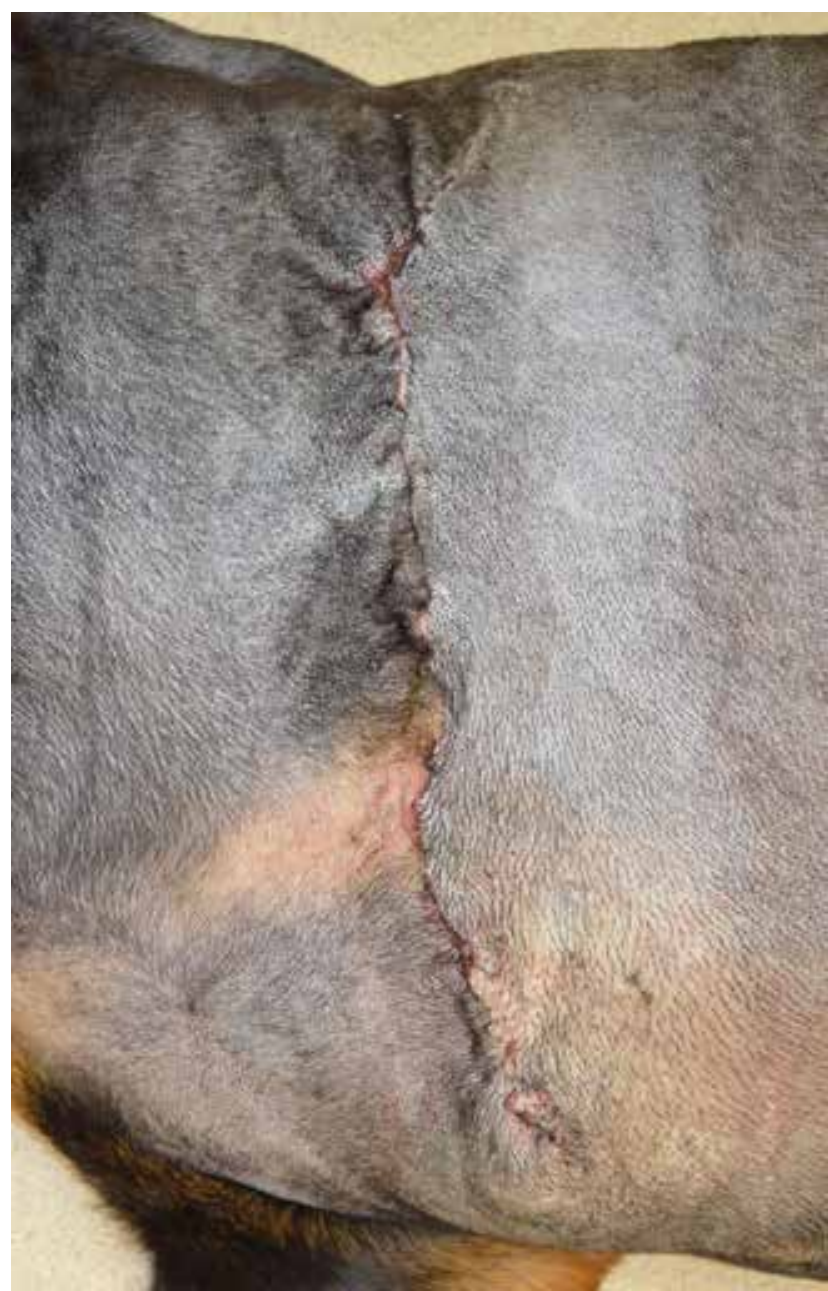

Figure 4. Closed surgical incision immediately after removal of the Prevena Peel \& Place dressing for closed incision management after 72 hours of negative pressure wound therapy.

clean, and there were no indications for seroma formation or any other wound healing complications (Figure 4). The dog walked well on three legs. He was discharged on cimicoxib for another three days.

The patient was presented for revaluation ten days after surgery. The dog walked well on three legs and was very excited. The surgical wound was dry, clean and not painful. There were no signs of seroma formation.

Five weeks after surgery, the dog was active and playful. The surgical wound had healed nicely, leaving only a discrete scar.

\section{DISCUSSION}

Closed incision management with NPWT is a relatively novel technique, utilized mainly by human plastic surgeons. It is applied on primary closed surgical skin incisions that have a high risk of postoperative complications such as seroma formation (Kilpadi and Cunningham, 2011; Stannard et al., 2012). The patient described in the case report was an active, large breed 
dog that underwent a limb amputation, and was therefore at high risk to develop wound healing complications. Postoperative management by CIM resulted in uneventful recovery and healing.

After limb amputation, substantial dead space might exist, and therefore seroma formation is not uncommon, especially in large breed dogs (Raske et al., 2015). A seroma develops due to the accumulation of a serohemorrhagic fluid, produced due to postoperative inflammation with bleeding and leakage from capillaries (Amsellem, 2011; Kilpadi and Cunningham, 2011). Moreover, movement at the surgical site plays an important causative role. To promote gradual resorption of a seroma, conservative measures, such as the application of hot and cold packs, ultrasound therapy and restriction of the patient's activity levels can be taken (Amsellem, 2011). Repeated aspiration of the fluid is not advisable as it may lead to iatrogenic inoculation of bacteria, resulting in abscess formation (Amsellem, 2011). In cases that do not respond to conservative management, surgical intervention, such as placement of a drain, is needed (Kilpadi and Cunningham, 2011).

Several preventive measures can be taken to minimize the risk of postoperative seroma formation. In this case report, careful apposition of the soft tissues was performed and the Prevena Incision Management System for CIM was applied after wound closure. Closed incision management is one of the newest applications of NPWT and is indicated to prevent or treat complications in high-risk wounds in humans (Stannard et al., 2012). Examples of high-risk wounds are wounds after high velocity trauma, surgical wounds in patients with comorbidities, median sternotomies, but also wounds after extensive and invasive surgery. It has been suggested that the compressive effect of NPWT and/or the minimal movement of the surgical area during NPWT result(s) in decreased edema and seroma development (Suh et al., 2016). Consequently, the risk of delayed wound healing and/or wound dehiscence is decreased (Amsellem, 2011; Suh et al., 2016). Furthermore, potential discomfort due to the presence of a seroma is avoided (Kilpadi and Cunningham, 2011). The indications for incisional NPWT in companion animals are similar to those in humans (Perry et al., 2015; Nolff and Meyer-Lindenberg, 2016). Since large breed dogs are at risk to develop a postoperative seroma after limb amputation, CIM with NPWT was applied in the present case.

Besides seroma prevention, CIM with NPWT may also prevent surgical site infections (SSI) (Stannard et al., 2012; Horch, 2015; Suh et al., 2016). Factors that elicit SSI are surgical trauma to the soft tissues, excessive blood loss and substantial release of pain mediators, and/or long surgery time (Straw and Withrow, 1996; Kirby and Mazuski, 2009; Widgerow and Kalaria, 2012; Raske et al., 2015). Infections slow down the healing process, resulting in weak suture lines and an increased risk of wound dehiscence
(Raske et al., 2015). Closed incision NPWT may prevent SSI because tissue perfusion is enhanced, while environmental contamination of the wound is prohibited (Stannard et al., 2012; Horch, 2015; Suh et al., 2016). Since limb amputation in large breed dogs is a rather lengthy surgery, perioperative administration of a broad-spectrum antibiotic therapy has been recommended to aid in the prevention of SSI (Amsellem, 2011). The dog in the current case report received only a prophylactic IV injection of a first-generation cephalosporin at the time of the anesthetic induction. A postoperative antibiotic treatment was not installed, as it is not necessary nor effective in further reducing the risk of SSI (Barie, 2000; Kirby and Mazuski, 2009; Raske et al., 2015). Proper pain management is important during, but also after surgery. Furthermore, prolonged recumbency of the patient on the operated side should be avoided since it exerts unwanted pressure on the surgical area (Raske et al., 2015).

Additional advantages of CIM with NPWT have been described. It has been reported that tension on both sides of the surgical incision is decreased in wounds treated by NPWT compared to those treated without NPWT. In addition, a good apposition of the incisional edges is established with NPWT (Wilkes et al., 2011).

Positive effects described in veterinary medicine so far include reduced digital swelling, and decreased fluid discharge in dogs and cats receiving CIM with NPWT after fracture repair compared to control patients that only received a Robert-Jones bandage (Perry et al., 2015). In addition, Nolff et al. (2015a) described the use of incisional NPWT in a staged procedure in a dog with complicated wound healing. After debridement, the open wound was treated with NPWT for two days. Then, the wound was primarily closed and subsequently treated successfully by incisional NPWT (Nolff et al., 2015a).

Before the application of CIM with NPWT, a drain needs to be placed to avoid postoperative seroma formation in cases with presumed dead space (Kilpadi and Cunningham, 2011). Passive drainage by e.g. a Penrose drain needs gravidity to be efficient, whereas an active drain removes wound fluid due to suction exerted by an external container under negative pressure (Balsa and Culp, 2015). A drain should exit the skin through a dedicated opening near the surgical incision,

Table 1. Halsted's principles of surgery (Adapted from: Slatter, 2003).

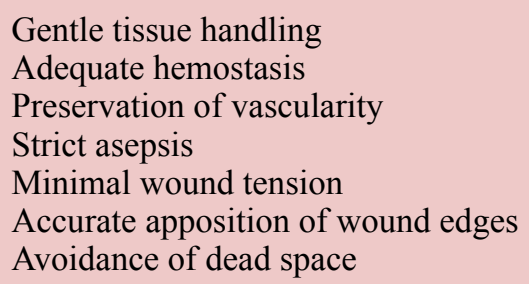


thereby necessitating additional undermining (Amsellem, 2011). One of the major complications of the placement of a drain is the risk of developing a SSI as the presence of a drain lowers the threshold for the number of microorganisms to induce infection, and encourages local inflammation as it is a foreign object (Eugster et al., 2004; Tobias and Johnston, 2013). In addition, passive drains may allow bacteria from the surroundings to mount into the wound alongside the drain surface (Balsa and Culp, 2015). Other problems related to drains include damage of vessels or tissue, metabolic problems due to excessive fluid loss, and pain induced by the tubing or by the exerted negative pressure in case of active drains (Tobias and Johnston, 2013).

It should be emphasized that the introduction of a novel concept, such as CIM with NPWT, should not inspire surgeons to no longer strictly adhere to the basic surgical Halsted's principles (Slatter, 2003; Mickelson et al., 2016) (Table 1). First of all, the surgeon needs to avoid overzealous tissue trauma. Muscles should be freed close to their insertion rather than by transection of muscle bellies, whenever possible. Furthermore, special attention should be paid to obtain adequate hemostasis while preserving the blood supply to the remaining tissues. After removal of the limb, all tissue planes should be approximated accurately in order to obliterate dead space as much as possible.

Points of concern when using NPWT are generally bleeding, irritation by or allergic reaction to the material, infection and technical issues such as a leak in the system (KCI Licensing, Inc., 2016b). To the authors' knowledge, there are few complications associated with the Prevena Incision Management System reported in studies that assessed the efficacy of CIM with NPWT. In a study by Howell et al. (2011), skin blistering was observed at the junction between the sponge and the adhesive tape, and another case of superficial skin necrosis in the area of the Prevena disc has been reported (Görgülü, 2015).

The manufacturer of Prevena ${ }^{\mathrm{TM}}$ listed some contraindications for use (KCI Licensing, Inc., 2016b). Since the skin interface layer contains silver, the dressing should not be applied in patients with hypersensitivity to silver. Furthermore, patients with open or dehisced surgical wounds are better candidates for traditional NPWT. Likewise, in patients with surgical incision lines that drain excessively, CIM with NPWT should not be applied as the Prevena canisters can only accept $45 \mathrm{ml}$.

In the present case, the CIM with NPWT was maintained for 72 hours. The manufacturer recommends a Prevena ${ }^{\mathrm{TM}}$ therapy of a minimum of two days and a maximum of seven days (KCI Licensing, Inc., 2016a). However, there are currently no clear criteria to decide when to discontinue the CIM. During hospitalization, the system has to be checked regularly, since loss of negative pressure due to small leaks is a common technical issue in veterinary patients (Howe, 2015).
Applying NPWT on a surgical incision after limb amputation was successful in avoiding seroma development in the dog described in this case report. More veterinary cases should be treated to define specific veterinary guidelines and to clarify specific mechanisms of CIM with NPWT.

\section{REFERENCES}

Amsellem, P. (2011). Complications of reconstructive surgery in companion animals. Veterinary Clinics of North America: Small Animal Practice 41, 995-1006.

Balsa, I.M., Culp, W.T. (2015). Wound care. Veterinary Clinics of North America: Small Animal Practice 45, 1049-1065.

Barie, P.S. (2000). Modern surgical antibiotic prophylaxis and therapy-less is more. Surgical Infections 1, 23-29.

Ben-Amotz, R., Lanz, O.I., Miller, J.M., Filipowicz, D.E., King, M.D. (2007). The use of vacuum-assisted closure therapy for the treatment of distal extremity wounds in 15 dogs. Veterinary Surgery 36, 684-690.

Birke-Sorensen, H., Malmsjo, M., Rome, P., Hudson, D., Krug, E., Berg, L., Bruhin, A., Caravaggi, C., Chariker, M., Depoorter, M. (2011). Evidence-based recommendations for negative pressure wound therapy: treatment variables (pressure levels, wound filler and contact layer)-steps towards an international consensus. Journal of Plastic, Reconstructive \& Aesthetic Surgery 64, S1-S16.

Divya, A., Patil, R., Kannan, N., Kesary, S.P.R. (2009). Fibrosarcoma of the mandible: case report of a unique radiographic appearance. Oral Radiology 25, 77-80.

Eugster, S., Schawalder, P., Gaschen, F., Boerlin, P. (2004). A prospective study of postoperative surgical site infections in dogs and cats. Veterinary Surgery 33, 542-550.

Fossum, T.W., Dewey, C.W., Horn, C.V., Johnson, A.L., MacPhail, C.M., Radlinsky, M.G., Schulz, K.S., Willard, M.D. (2013). Amputation. In: Small Animal Surgery. (Texas: Elsevier), 1400-1402.

Görgülü, T. (2015). A complication of management of closed incision with negative-pressure wound therapy. Aesthetic Surgery Journal 35, 113-115.

Guille, A.E., Tseng, L.W., Orsher, R.J. (2007). Use of vacuum-assisted closure for management of a large skin wound in a cat. Journal of the American Veterinary Medical Association 230, 1669-1673.

Horch, R.E. (2015). Incisional negative pressure wound therapy for high-risk wounds. Journal of Wound Care 24, 21-28.

Howe, L.M. (2015). Current concepts in negative pressure wound therapy. Veterinary Clinics of North America: Small Animal Practice 45, 565-584.

Howell, R.D., Hadley, S., Strauss, E., Pelham; F.R. (2011). Blister formation with negative pressure dressings after total knee arthroplasty. Current Orthopaedic Practice 22, 176-179.

KCI Licensing (2016a). Prevena evidence brochure. Acelity. Ed. San Antonio, USA, KCI Licensing, Inc..

KCI Licensing (2016b). Prevena incision management system: Application instructions for clinicians only. Acelity. Ed. San Antonio, USA, KCI Licensing, Inc..

Kilpadi, D.V., Cunningham, M.R. (2011). Evaluation of closed incision management with negative pressure wound therapy (CIM): hematoma/seroma and involve- 
ment of the lymphatic system. Wound Repair and Regeneration 19, 588-596.

Kirby, J.P. and Mazuski, J.E. (2009). Prevention of surgical site infection. Surgical Clinics of North America 89, 365-389.

Li, Z., Yu, A. (2014). Complications of negative pressure wound therapy: A mini review. Wound Repair and Regeneration 22, 457-461.

Mickelson, M.A., Mans, C., Colopy, S.A. (2016). Principles of wound management and wound healing in exotic pets. Veterinary Clinics of North America: Exotic Animal Practice 19, 33-53.

Mullally, C., Carey, K., Seshadri, R. (2010). Use of a nanocrystalline silver dressing and vacuum-assisted closure in a severely burned dog. Journal of Veterinary Emergency and Critical Care 20, 537-537.

Nolff, M., Flatz, K., Meyer-Lindenberg, A. (2015a). Preventive incisional negative pressure wound therapy (Prevena) for an at-risk-surgical closure in a female Rottweiler. Schweizer Archiv für Tierheilkunde 157, 105-109.

Nolff, M., Meyer-Lindenberg, A. (2016). Negative pressure wound therapy in small animal medicine. Tierärztliche Praxis Kleintiere 44, 26-37.

Nolff, M.C., Fehr, M., Bolling, A., Dening, R., Kramer, S., Reese, S., Meyer-Lindenberg, A. (2015b). Negative pressure wound therapy, silver coated foam dressing and conventional bandages in open wound treatment in dogs. A retrospective comparison of 50 paired cases. Veterinary and Comparative Orthopaedics and Traumatology (VCOT) 28, 30-38.

Ingargiola, M.J., Daniali, L.N., Lee, E.S. (2013). Does the application of incisional negative pressure therapy to high-risk wounds prevent surgical site complications? A systematic review. ePlasty 13.

Or, M., Van Goethem, B., Kitshoff, A., Koenraadt, A., Schwarzkopf, I., Bosmans, T., de Rooster, H. (2017). Negative pressure wound therapy using polyvinyl alcohol foam to bolster full-thickness mesh skin grafts in dogs. Veterianry Surgery 46, 389-395.

Perry, K.L., Rutherford, L., Sajik, D.M., Bruce, M. (2015).
A preliminary study of the effect of closed incision management with negative pressure wound therapy over high-risk incisions. BMC Veterinary Research 11, 279.

Pitt, K.A., Stanley, B.J. (2014). Negative pressure wound therapy: experience in 45 dogs. Veterinary Surgery 43, 380-387.

Raske, M., McClaran, J., Mariano, A. (2015). Short-term wound complications and predictive variables for complication after limb amputation in dogs and cats. Journal of Small Animal Practice 56, 247-252.

Slatter, D.H. (2003). Principles of surgical asepsis. In: Holmberg D.L. (editor). Textbook of Small Animal Surgery. Third edition, Elsevier Health Sciences, 150-151.

Stanley, B.J., Pitt, K.A., Weder, C.D., Fritz, M.C., Hauptman, J.G., Steficek, B.A. (2013). Effects of negative pressure wound therapy on healing of free full-thickness skin grafts in dogs. Veterinary Surgery 42, 511-522.

Stannard, J.P., Gabriel, A., Lehner, B. (2012). Use of negative pressure wound therapy over clean, closed surgical incisions. International Wound Journal 9, 32-39.

Straw, R.C., Withrow, S.J. (1996). Limb-sparing surgery versus amputation for dogs with bone tumors. Veterinary Clinics of North America: Small Animal Practice 26, 135-143.

Suh, H., Lee, A.-Y., Park, E.J., Hong, J.P. (2016). Negative pressure wound therapy on closed surgical wounds with dead space: animal study using a swine model. Annals of Plastic Surgery 76, 717-722.

Tobias, K.M., Johnston, S.A. (2013). Bandages and drains. In: Grambow Campbell, B. (editor). Veterinary Surgery: Small Animal. First edition, Elsevier Health Sciences, 227-230.

Widgerow, A.D., Kalaria, S. (2012). Pain mediators and wound healing: establishing the connection. Burns 38, 951-959.

Wilkes, R.P., Kilpad, D.V., Zhao, Y., Kazala, R., McNulty, A. (2011). Closed incision management with negative pressure wound therapy (CIM): biomechanics. Surgical Innovation 19, 67-75. 